\title{
EFFECT OF LANDSCAPE METRICS ON WATER QUALITY OVER THREE DECADES: A CASE STUDY OF THE AVE RIVER BASIN, PORTUGAL
}

\author{
ANTÓNIO CARLOS PINHEIRO FERNANDES ${ }^{1}$, LISA MARIA DE OLIVEIRA MARTINS ${ }^{1}$, \\ LUÍS FILIPE SANCHES FERNANDES ${ }^{1} \&$ FERNANDO ANTÓNIO LEAL PACHECO ${ }^{2}$ \\ ${ }^{1} \mathrm{CITAB}$ - Centre for the Research and Technology of Agro-Environment and Biological Sciences, \\ University of Trás-os-Montes and Alto Douro, Portugal \\ ${ }^{2}$ CQVR - Vila Real Chemistry Research Centre, University of Trás-os-Montes and Alto Douro, Portugal
}

\begin{abstract}
Due to intense industrial and urban activity Ave River Basin, Portugal was once tagged as one of the most polluted in Europe. Besides point source pressures are the most evident threat to water quality in this river basin, in the present study, the effect of landscape on water quality was analysed. From a hydrological database, the concentration surface water parameters was extracted, comprehended between 1988 and 2016. The average concentrations in each sampling site for each hydrological year was calculated. The averages were correlated to 15 landscape metrics by using the Spearman's rank correlation coefficient, over the analysed hydrological years. For each landscape metric, the percentage of correlations with surface water parameters for each hydrological year that had statistical significance $(\mathrm{p} \leq 0.05)$ was counted, and the same analysis was made for each surface water parameter. The area occupied by artificial surfaces increased the contaminant concentrations in $65.3 \%$ of the correlations while the edge density increased by $62 \%$. For forested areas, the edge density and occupied area had, respectively, $56.0 \%$ and $66.0 \%$, of correlations that decreased contaminant concentrations. Conductivity was the parameter that has most linked to landscape metrics since, $52 \%$ increased the concentration, $21 \%$ decreased, while the remaining $27 \%$ did not have statistical significance. Oxygen demands, total suspended solids, different nitrates forms, total orthophosphate and coliforms were acceptably correlated, with percentages ranging from $20 \%$ to $44 \%$. Only heavy metals were poorly correlated, since the percentage of correlations that varied the concentrations was lower than $8 \%$. This study allowed us to understand that in an urbanised river basin, where point source pressures are the dominant pollution source, landscape metrics also have an effect on water quality and can become a threat to hydric resources.
\end{abstract}

Keywords: Spearman's rank correlation coefficient, water quality, ArcGIS, Ave River Basin, landscape metrics.

\section{INTRODUCTION}

The management of hydric resources is one challenge that has alongside humanity for thousands of years. Not only the availability of hydric resources but also the quality is a concern that emerged with demographic expansion and economic development. Since many threats to water quality have been arising, researchers have been conducting their studies in the scope of improving treatment technologies [1], prevention and mitigation strategies [2]. To study water quality (WQ) is necessary to comprehend that there is a multitude of interactions [3]-[7] and a vast type of different pollution sources that will end up releasing contaminants in hydric resources [8], which is essential knowledge to support the management of hydric resources [9]. In general, two types of pollution sources exist, point source (PS) and non-point source (NPS). Effluent discharges are the clearest point source pressures in hydric resources [10]. Besides the purpose of treatment stations is to reduce contamination loads, when treatment stations are not under proper functioning hydric resources become heavily contaminated. Commonly, effluents from domestic sewage contain high loads of organic compounds [11], while in industrial effluents, the composition is highly 
variable. Metallurgic and textile industries may release heavy metals [12], [13], pharmaceutical industries can release different chemical compounds [14], and food industries can release high loads of organic compounds [15], [16]. The diffuse sources (also called NPS) are large areas that can contain contaminants that are carried to rivers through surface runoff mechanisms. Such areas might be agricultural areas or livestock farms [17]. In agricultural fields, the pollution comes from the application of herbicides and pesticides [18], and in livestock areas, manure is a contamination source [19]. Many studies have been executed in the scope of the impact of NPS in WQ. In such studies, landscape metrics have been used as variables that characterise diffuse pollution sources. The composition of a landscape allows to interpret which are the dominant land uses, but the configuration,( for example, edge density and number of patches) are also key aspects to interpret if a landscape is vulnerable or not to diffuse pressures [20].

The present study takes place in an urbanised river basin located in the northwest region of Portugal, Ave River Basin (Fig. 1). Due to intense anthropogenic activity, during the second half of the 20th century, industrial effluent discharges without proper treatment. For such reasons, it became one of the most polluted in Europe [21]. This problematic caught the attention of several experts to study this problem. In pioneer studies, heavy metals concentration was measured in surface waters, aquatic fauna and sediments, to evidence the problem [13], [22]. Due to an ambitions remediation program, the concentrations dropped in the begging of the 21 st century [23]. However, in more recent studies, it was revealed that PS was still contaminating the river basin and also diffuse pressures became another concern [24]-[26].

The effects of landscape metrics on surface water parameters from 1988 to 2016 in Ave River Basin were studied, with the purpose of understanding which contaminants are related to landscape, and which landscape metrics are the one threat to WQ.

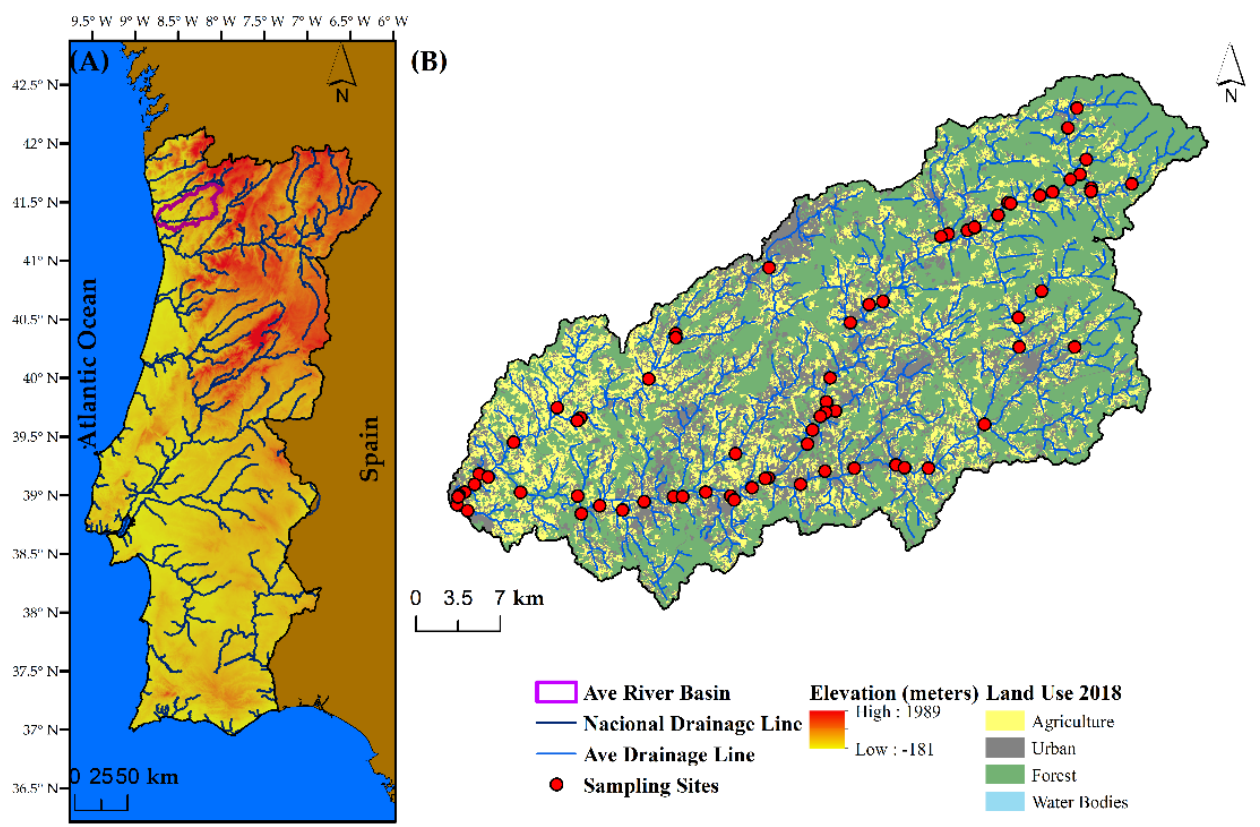

Figure 1: Ave River Basin location. (a) Portugal; and (b) Ave River Basin land use of 2018, and location of SWP sampling sites. 


\section{METHODOLOGY}

The relation between landscape metrics and surface water parameters along different hydrological years (HY) was analysed by using Spearman's correlation rank coefficient. The first step was to delineate the Ave River Basin, drainage lines and also the drainage area of each WQ sampling site, by using ArcMap [27] and ArcHydro tools [28]. The location of the sampling sites and also the measurements of different surface water parameters (SWP) was downloaded from the Portuguese hydrological database SNIRH [29]. Table 1 represents the number of sampling sites for each SWP according to the HY.

The land cover was downloaded from the Portuguese Territorial database. For each year and drainage area, it was calculated landscape metrics by using a python toolbox [30]. Metrics were calculated for generic land uses, agriculture areas (AGR), artificial surfaces (ART) and also forest and semi-natural areas (FOR). The calculated metrics were the number of patches (npc), the percentage of area occupied (pz), the edge density (ed) and also the percentage of edges that are shared with two different types of land use (cce).

The Spearman's correlation rank coefficient $\left(\mathrm{r}_{\mathrm{s}}\right)$, measures monotonic relation between the paired variables. This coefficient varies from -1 to 1 . When $r_{s}$ is close to 0 , the correlation is weak, while if the value is closer to -1 or 1 it means that the correlation is strong. In order to know if a correlation is statistically significant, is crucial to analyse the probability to reject the null hypothesis, which is dependent on the sample size. For two-tailed probabilities and a statistical significance of 0.05 , the minimum sample size to achieve a statistically significant correlation is 5 . Since for that sample size is necessary to have the maximum correlation $\left(\mathrm{r}_{\mathrm{s}}=1\right.$ or $\left.\mathrm{r}_{\mathrm{s}}=1\right)$ it was analysed only the correlations with at least six samples.

\section{RESULTS AND DISCUSSION}

For the present study, it was calculated the correlations between the 15 LSM with 14 SWP for the 29 analysed hydrological years. The correlations were counted, and it was calculated the percentage of correlations that had statistical significance. Tables 2 and 3 present the positive and negative correlations, respectively. For the percentage calculation, it was considered only correlations that had six or more samples. In Tables 2 and 3, the centred cells represent the percentage of hydrological years were the correlation was statistically significant. The last columns are the percentage of hydrological years among all metrics for the respective SWP, while in the last row is made the same analysis but for each LSM. For example, conductivity is a parameter that had more than five samples in 27 hydrological years. By looking to the percentage of correlations between conductivity with npc_(ART) in Table 2, the percentage of correlations is approximately $59.3 \%$, which means that in 16 of the 27 analysed hydrological years, the correlation between this two variables is positive and statistically significant. In the last row of Table 2, the percentage of correlations among all LSM with conductivity is approximately $51.9 \%$. Which means that in a total of 405 correlations (15 LSM in $27 \mathrm{HY}$ ), conductivity was positively correlated with statistical significance in 210 correlations, while 85 of the correlations (21\% in Table 3 ) were negative and statistically significant, but the remaining 110 correlations were not statistically significant. By analysing the percentage of correlations of npc_(ART) in Table 2, is seen that the percentage of correlations is approximately $45.1 \%$. This percentage is calculated by the total number of correlations among all SWP in the available hydrological years that had more than five measurements which is in total 297 correlations, and $45.1 \%$ of the total number of calculated correlations is 134 . 
Table 1: Surface water parameters and the number of sampling sites with data.

\begin{tabular}{|c|c|c|c|c|c|c|c|c|c|c|c|c|c|c|}
\hline $\begin{array}{c}\text { Hydrological } \\
\text { year }\end{array}$ & $\begin{array}{l}\frac{n}{0} \\
0 \\
0 \\
0 \\
0 \\
0 \\
0 \\
0 \\
0 \\
0 \\
0 \\
0 \\
0 \\
0 \\
0 \\
0\end{array}$ & 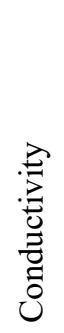 & 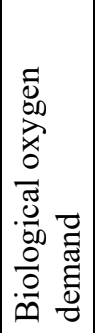 & 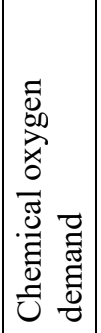 & 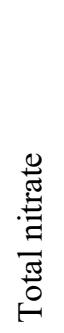 & 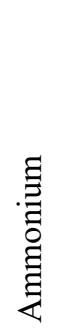 & 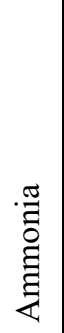 & $\begin{array}{l}\frac{0}{\pi} \\
\frac{\pi}{2} \\
0 \\
0 \\
0 \\
\frac{0}{2} \\
0 \\
0 \\
0 \\
0\end{array}$ & 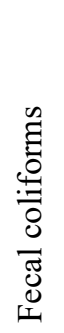 & 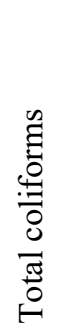 & 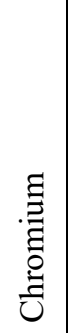 & $\underset{\mathscr{J}}{\widetilde{\Xi}}$ & 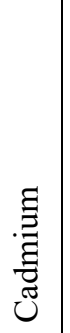 & $\begin{array}{l}\grave{\Xi} \\
\stackrel{0}{0} \\
\stackrel{\vec{e}}{\Sigma}\end{array}$ \\
\hline $1988-1989$ & 3 & 3 & 3 & 0 & 0 & 3 & 0 & 0 & 3 & 0 & 0 & 0 & 0 & 0 \\
\hline 1989-1990 & 6 & 6 & 6 & 6 & 6 & 6 & 0 & 6 & 6 & 6 & 0 & 0 & 0 & 0 \\
\hline 1990-1991 & 6 & 6 & 6 & 6 & 6 & 6 & 1 & 6 & 6 & 6 & 5 & 5 & 5 & 5 \\
\hline 1991-1992 & 6 & 6 & 6 & 6 & 6 & 6 & 0 & 6 & 6 & 0 & 0 & 0 & 0 & 0 \\
\hline 1992-1993 & 1 & 3 & 1 & 3 & 3 & 3 & 0 & 3 & 3 & 2 & 0 & 0 & 0 & 0 \\
\hline 1993-1994 & 15 & 15 & 15 & 15 & 15 & 15 & 0 & 15 & 15 & 9 & 0 & 0 & 0 & 0 \\
\hline 1994-1995 & 15 & 15 & 15 & 15 & 15 & 15 & 15 & 15 & 15 & 9 & 0 & 0 & 0 & 0 \\
\hline 1995-1996 & 15 & 15 & 15 & 15 & 15 & 15 & 15 & 15 & 15 & 9 & 0 & 0 & 0 & 0 \\
\hline 1996-1997 & 16 & 17 & 16 & 17 & 17 & 17 & 17 & 17 & 17 & 11 & 0 & 0 & 0 & 0 \\
\hline $1997-1998$ & 17 & 17 & 17 & 17 & 17 & 17 & 17 & 17 & 17 & 11 & 0 & 0 & 0 & 0 \\
\hline 1998-1999 & 20 & 20 & 20 & 20 & 20 & 20 & 20 & 20 & 20 & 11 & 2 & 2 & 2 & 2 \\
\hline 1999-2000 & 18 & 18 & 18 & 17 & 18 & 18 & 19 & 16 & 17 & 6 & 6 & 6 & 6 & 6 \\
\hline $2000-2001$ & 10 & 7 & 10 & 7 & 10 & 10 & 11 & 7 & 7 & 7 & 5 & 5 & 5 & 5 \\
\hline $2001-2002$ & 11 & 9 & 9 & 8 & 8 & 9 & 10 & 8 & 8 & 8 & 9 & 11 & 11 & 11 \\
\hline $2002-2003$ & 12 & 9 & 9 & 8 & 9 & 9 & 10 & 8 & 8 & 8 & 9 & 9 & 9 & 9 \\
\hline 2003-2004 & 12 & 9 & 9 & 8 & 9 & 9 & 10 & 8 & 8 & 8 & 9 & 9 & 9 & 9 \\
\hline 2004-2005 & 13 & 13 & 13 & 12 & 12 & 13 & 0 & 12 & 12 & 12 & 12 & 12 & 12 & 12 \\
\hline $2005-2006$ & 13 & 13 & 13 & 12 & 12 & 13 & 0 & 12 & 12 & 12 & 12 & 12 & 12 & 12 \\
\hline 2006-2007 & 14 & 14 & 14 & 13 & 14 & 14 & 0 & 13 & 12 & 12 & 12 & 12 & 12 & 12 \\
\hline $2007-2008$ & 14 & 14 & 14 & 12 & 12 & 14 & 14 & 12 & 11 & 11 & 11 & 0 & 0 & 0 \\
\hline 2008-2009 & 27 & 24 & 23 & 22 & 28 & 28 & 24 & 22 & 21 & 21 & 21 & 0 & 0 & 0 \\
\hline 2009-2010 & 31 & 31 & 31 & 30 & 30 & 31 & 23 & 25 & 23 & 23 & 23 & 14 & 14 & 14 \\
\hline $2010-2011$ & 20 & 21 & 22 & 19 & 23 & 23 & 5 & 16 & 14 & 14 & 0 & 0 & 0 & 0 \\
\hline 2011-2012 & 19 & 18 & 19 & 16 & 16 & 17 & 5 & 16 & 14 & 14 & 16 & 16 & 16 & 15 \\
\hline $2012-2013$ & 17 & 17 & 17 & 17 & 17 & 17 & 5 & 16 & 0 & 0 & 0 & 0 & 0 & 0 \\
\hline 2013-2014 & 28 & 28 & 28 & 15 & 28 & 28 & 5 & 13 & 0 & 0 & 13 & 12 & 13 & 13 \\
\hline 2014-2015 & 29 & 29 & 29 & 8 & 29 & 29 & 0 & 6 & 0 & 0 & 0 & 0 & 0 & 0 \\
\hline $2015-2016$ & 8 & 13 & 9 & 8 & 9 & 8 & 0 & 6 & 0 & 0 & 0 & 0 & 0 & 0 \\
\hline $2016-2017$ & 8 & 8 & 8 & 0 & 8 & 8 & 0 & 0 & 0 & 0 & 0 & 0 & 0 & 0 \\
\hline
\end{tabular}

By comparing Table 2 with Table 3, is seen in overall that landscape metrics have a stronger influence in the increase of SWP rather than in the decrease. For example, the percentage of correlations that increase conductivity (51.9\%) is lower than the percentage that decreases it $(21.0 \%)$, and in other SWP the percentages of positive correlations are also higher. According to Table 2 (last column), conductivity is mostly increased by landscape 


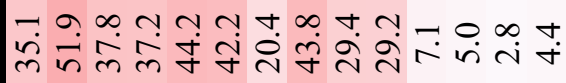

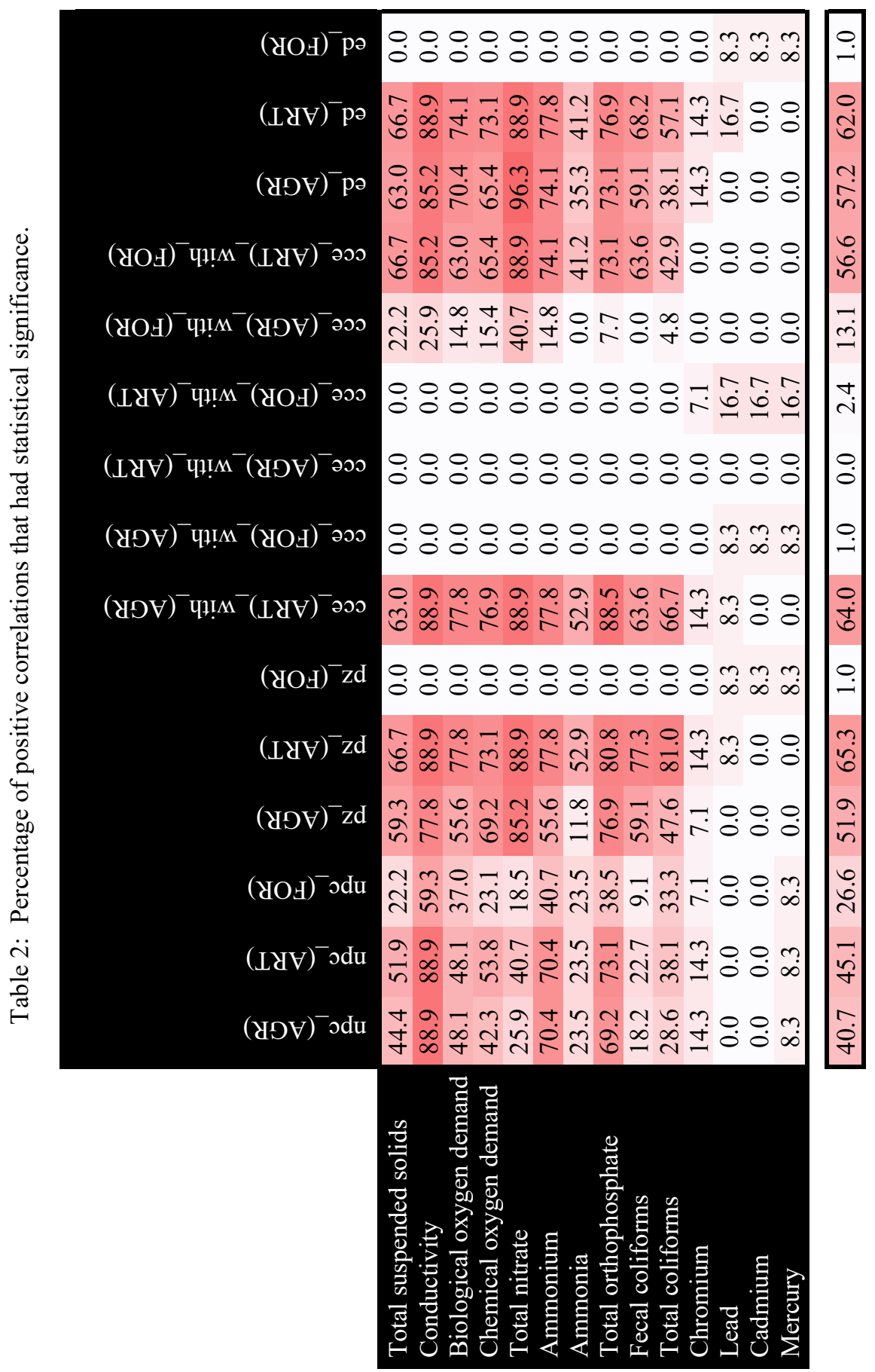




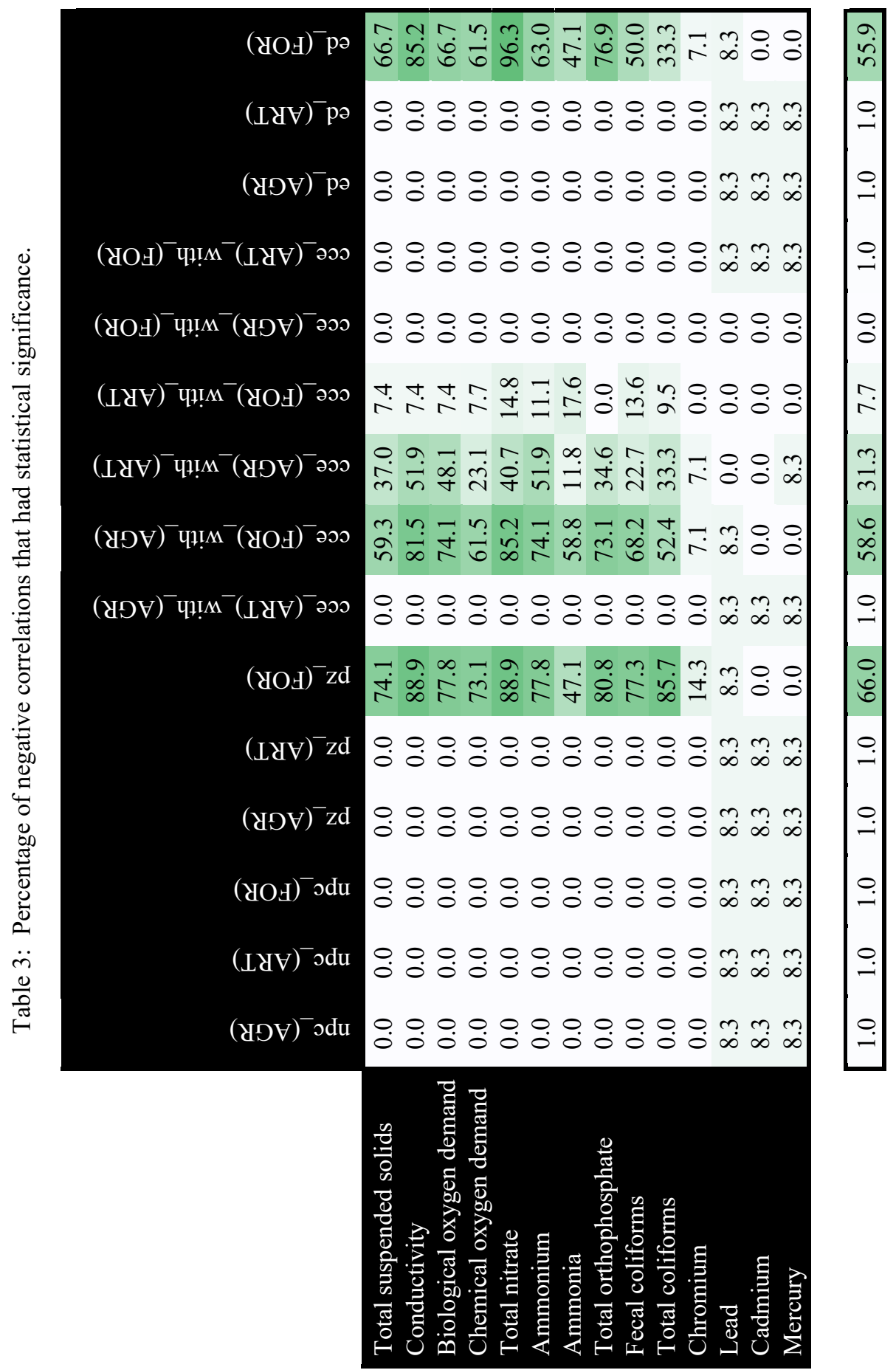


metrics $51.9 \%$, followed by parameters related to nutrients ( $\mathrm{N}$ and $\mathrm{P})$, nitrate $(44.2 \%)$, total orthophosphate (43.8\%) and also ammonium with (42.2\%). With lower percentages, oxygen demands, both $\mathrm{BOD}_{5}$ and $\mathrm{COD}$ are still affected by landscape metrics with a percentage of 37.8 and $37.2 \%$, respectively. Total suspended solids percentage is $35.1 \%$, coliforms are also increased in 29.4\% and 29.2, faecal and total respectively. Ammonia is the parameter related to $\mathrm{N}$ forms that is less influenced by landscape metrics with a percentage of $20.4 \%$, and heavy metals are less correlated to LSM since the percentage of positive correlations are the lowest, ranging from $7.1 \%$ to $2.8 \%$.

The parameters that are mostly decreased by LSM (Table 3 last column) are total nitrate $(21.7 \%)$ and conductivity (21.0\%). Other parameters have percentages that vary from $18.5 \%$ to $12.2 \%$, expect heavy metals that have lower percentages, ranging from $6.7 \%$ and $2.4 \%$.

In the last row of Tables 2 and 3 the percentage of correlations associated with each metric is shown. Some contrast metrics might look identic when applied to the same pair of land uses, for example, cce_(AGR)_with_(FOR) and cce_(FOR)_with_(AGR). However, they are different since in the first case is the percentage of forested edges that are shared with agriculture edges, while the second metric is the percentage of agricultural edges that are shared with forestry edges. From the 15 LSM only four have a notorious impact in the decrease of contaminants concentrations, pz_(FOR) (66.0\%), cce_(FOR)_with_(AGR) (58.6\%), ed_(FOR) (55.9\%) and unexpectedly the cce_(AGR)_with_(ART) (31.3\%). There are eight metrics that increase the SWP:pz_(ART) (65.3\%), cce_(ART)_with_(AGR) (64\%), ed_(ART) (62\%), ed_(AGR) (57.2\%), cce_(ART)_with_(FOR) (56.6\%), pz_(AGR) $(51.9 \%)$, npc_(ART) (45.1\%) and npc_(AGR) (40.7\%). The remaining three metrics, npc_(FOR), cce_(AGR)_with_(FOR) and cce_(FOR)_with_(ART), can be assumed as noneffective since the percentages that increase and decrease SWP are much lower when compared to the other LSM.

In the main matrix of Tables 2 and 3, it can be seen in detail which SWP are related to LSM. For heavy metals the percentages of correlations are quite low, varying from $16.7 \%$ to $0.0 \%$, so there is not any particular LSM that can be related to heavy metals. The npc_(AGR) and npc_(ART) are both related to the increase of conductivity, orthophosphate and ammonium. The pz_(AGR) is linked to SWP with the expectation of ammonia and heavy metals, while the pz_(ART) and cce_(ART)_with_(AGR) are not linked to heavy metals. The cce_(ART)_with_(FOR) and ed_(AGR) are less linked to ammonia and total coliforms, and not linked to heavy metals, while ed_(ART) is more linked to the increase of total coliforms.

The pz_(FOR) is the metric that is mostly related to the decrease of SWP, and it decreases all SWP (except heavy metals) since the percentage of correlations ranges from $88.9-47.1 \%$. The cce_(FOR)_with_(AGR) also decreases the SWP but with a shorter range of 85.2-52.4\% (except heavy metals). The cce_(AGR)_with_(ART) decreases, in general, the SWP but seen in detail there are SWP that are more related to this metric, specific conductivity and ammonium both with $51.9 \%$ and BOD with $48.1 \%$. The ed_(FOR) is another LSM that had a strong influence in the decrease of SWP. However, it has high variability in the percentages of particular SWP, since in the decrease of nitrates the percentage is $96.3 \%$, for conductivity is $82.5 \%$, orthophosphate is $76.9 \%$, and for the reaming SWP is lower than $70 \%$, and also has no influence in heavy metals.

\section{DISCUSSION}

The used methodology allowed to understand which are the effects of landscape metrics in Ave River Basin. The analysis consisted in summarize the correlations between LSM and SWP in during many hydrological years, in order to treat the effects for an extended period. 
In general, the metrics have a substantial effect on the increase of contaminant concentrations rather than in the decrease. This is an expected result since there were used only three types of land use, of which ART and AGR usually have a negative impact on WQ, while FOR increases WQ [31].

This study allowed to understand which SWP are associated to LSM. By summing the respective percentages of Tables 2 and 3 , is calculated the total percentage of statistically significant correlations. Therefore, conductivity and total nitrates are the variables that are more influenced by landscape metrics, since the sum of percentages is the highest, respectively $72.8 \%$ and $65.9 \%$. Since electrical conductivity is a measure of ions is a parameter that portrays many contaminants surface water, which are linked to landscape metrics. The presence of nutrients is commonly accessed in landscape metrics studies [32], and also, in this case, the concentration of nitrates is linked to landscape metrics, and also total orthophosphate, which is one of the phosphorous. Oxygen demands are also linked in other studies with landscape metrics [33]-[35], in the present study BOD (56.1\%) and COD $(52.3 \%)$ are linked to LSM. The total suspended solids is also another parameter that is related to LSM, since the total percentage is $51.4 \%$, while the others have percentages lower than $50 \%$, possibly because they are more linked to point source pressures, which reflects in low correlations with LSM [36]. Total coliforms and faecal have total percentages of $43.5 \%$ and $44.9 \%$, respectively, besides this contaminant can be from livestock origin, it can be more linked to domestic sewage [37]. Ammonia can be released into surface water from different sources, such as fertilizer and also from industrial applications [38]. Since the total percentage is $32.6 \%$, it can be assumed that in the Ave River Basin is more linked to point source pressures rather than to diffuse emissions. The total percentage of the studied heavy metals ranges from $11.7 \%$ (lead) to $7.8 \%$ (cadmium), which means that the presence of this SWP is intrinsically linked to point sources pressures, as other studies have revealed for the studied river basin [13], [22], [39].

The results led to understand that the landscape metrics that play a dominant role in the river basin WQ are, the pz_(FOR) and pz_(ART), since pz_(FOR) decreases the concentration of SWP in $66 \%$ of the correlations while pz_(ART) increases the SWP in $65.9 \%$. Clearly, these variables expose the effect of natural areas vs anthropogenic regions, because in forestry areas found freshwaters with high quality [40]. Besides, urban areas can also be linked to point source pressures, urban areas are impervious, and the drainage can be routed surface waters, which is a form of diffuse urban pressure [41]. Besides the composition of artificial surfaces and forestry areas has an impact in Ave River Basin, other metrics evidenced influence on SWP, and also the ed_(ART) increases SWP with a percentage of positive correlations of $62.0 \%$. The percentage of agricultural edges that are shared with artificial surfaces, cce_(ART)_with_(AGR) has a strong impact, since the percentage of correlations that decrease WQ is $64.0 \%$. This was expected since agricultural areas, and artificial surfaces are land use types that commonly decrease WQ [31]. On the other hand, the cce_(AGR)_with_(ART) revealed 31.3\% negative correlations which is hard to explain. Separately the ed_(AGR) also revealed a degradation effect with $57.2 \%$ positive correlations. Nevertheless, the percentage of agricultural edges that are shared with forestry, cce_(FOR)_with_(AGR), revealed a positive impact on WQ, since the percentage of negative correlations $(58.6 \%)$. It is curious that edge density of forests, ed_(FOR), has a slightly lower percentage, $(55.9 \%)$. Other authors have reached a similar result [42], and this shows that agricultural fields that are surrounded by forests might not be harmful to hydric resources, by function as sinks for the contaminant flow. However, the percentage of forested areas that are shared with urban areas cce_(ART)_with_(FOR), has a negative impact on WQ, possibly because the effect of urban areas overcomes forestry regions. 


\section{CONCLUSION}

The results, clearly evidenced that the relations between LSM and SWP is highly variable depending on the metric and the parameter. The results clearly showed that in Ave River Basin, urban areas and also agricultural surfaces degrade WQ, while forestry land use can improve WQ. In practical terms, is necessary to increase forested areas in spread shapes, increasing edge density and total area. While for urban areas besides, it is hard to decrease the area occupied, is necessary to at least reduce the urban sprawl. In agricultural areas is essential to surround them with forests, in order to promote a natural barrier for the contaminant flow. For the biggest part of the analysed SWP, conscious land use changes might reduce the contamination into sustainable values. However, to reduce the contamination of ammonia and heavy metals is necessary to implement measures that are beyond landscape metrics, which can be the implementation of improved effluent treatment technologies.

\section{ACKNOWLEDGEMENTS}

This research was funded by the INTERACT project - "Integrated Research Environment, Agro-Chain and Technology", no. NORTE-01-0145-FEDER-000017, in its line of research entitled BEST, co-financed by the European Regional Development Fund (ERDF) through NORTE 2020 (North Regional Operational Program 2014/2020). For the authors integrated with the CITAB Research Centre, it was further financed by the FEDER/COMPETE/POCI - Operational Competitiveness and Internationalisation Programme, under Project POCI-010145-FEDER-006958, and by the National Funds of FCT - Portuguese Foundation for Science and Technology, under the project UID/AGR/04033/2020. For the author integrated in the CQVR, the National Funds of FCT - Portuguese Foundation for Science and Technology, under the project UID/QUI/00616/2019, supported the research. Financial support was also provided by the FCT-Portuguese Foundation for Science and Technology (Grant: SFRH/BD/146151/2019) to António Fernandes.

\section{REFERENCES}

[1] Trösch, W., Water treatment. Technology Guide: Principles - Applications - Trends, Springer Science and Business Media, pp. 394-397, 2009.

[2] Taylor, S.D., He, Y. \& Hiscock, K.M., Modelling the impacts of agricultural management practices on river water quality in Eastern England. J. Environ. Manage., 180, 2016.

[3] Pacheco, F.A.L., Martins, L.M.O., Quininha, M., Oliveira, A.S. \& Sanches Fernandes, L.F., An approach to validate groundwater contamination risk in rural mountainous catchments: The role of lateral groundwater flows. Methods X, 2018.

[4] Nas, S.S. \& Nas, E., Water quality modeling and dissolved oxygen balance in streams: A point source Streeter-Phelps application in the case of the Harsit stream. Clean Soil, Air, Water, 2009.

[5] Vannote, R.L., Minshall, G.W., Cummins, K.W., Sedell, J.R. \& Cushing, C.E., The river continuum concept. Can. J. Fish. Aquat. Sci., 1980.

[6] Martins, L., Pereira, A., Oliveira, A., Fernandes, A., Sanches Fernandes, L.F. \& Pacheco, F.A.L., An assessment of groundwater contamination risk with radon based on clustering and structural models. Water, 11, p. 1107, 2019.

[7] Sousa, J.C.G., Ribeiro, A.R., Barbosa, M.O., Ribeiro, C., Tiritan, M.E., Pereira, M.F.R. \& Silva, A.M.T., Monitoring of the 17 EU watch list contaminants of emerging concern in the Ave and the Sousa Rivers. Sci. Total Environ., 2019. 
[8] Sanches Fernandes, L.F., Fernandes, A.C.P., Ferreira, A.R.L., Cortes, R.M.V. \& Pacheco, F.A.L., A partial least squares: Path modeling analysis for the understanding of biodiversity loss in rural and urban watersheds in Portugal. Sci. Total Environ., 626, pp. 1069-1085, 2018.

[9] Gupta, S.K., Modern Hydrology and Sustainable Water Development, 2010.

[10] Garnier, J., Brion, N., Callens, J., Passy, P., Deligne, C., Billen, G., Servais, P. \& Billen, C., Modeling historical changes in nutrient delivery and water quality of the Zenne River (1790s-2010): The role of land use, waterscape and urban wastewater management. J. Mar. Syst., 2013.

[11] Hayet, C., Saida, B.A., Youssef, T. \& Hédi, S., Study of biodegradability for municipal and industrial Tunisian wastewater by respirometric technique and batch reactor test. Sustain. Environ. Res., 26, pp. 55-62, 2016.

[12] Sheoran, A.S. \& Sheoran, V., Heavy metal removal mechanism of acid mine drainage in wetlands: A critical review. Miner. Eng., 19, pp. 105-116, 2006.

[13] Gonçalves, E.P.R., Boaventura, R.A.R. \& Mouvet, C., Sediments and aquatic mosses as pollution indicators for heavy metals in the Ave River Basin (Portugal). Sci. Total Environ., 1992.

[14] Hernando, M.D., Mezcua, M., Fernández-Alba, A.R. \& Barceló, D., Environmental risk assessment of pharmaceutical residues in wastewater effluents, surface waters and sediments. Proceedings of the Talanta, 2006.

[15] Grizzetti, B., Bouraoui, F. \& De Marsily, G., Assessing nitrogen pressures on European surface water. Global Biogeochem. Cycles, 22, 2008.

[16] Serrano-Grijalva, L., Sánchez-Carrillo, S., Angeler, D.G., Sánchez-Andrés, R. \& Álvarez-Cobelas, M., Effects of shrimp-farm effluents on the food web structure in subtropical coastal lagoons. J. Exp. Mar. Bio. Ecol., 402, pp. 65-74, 2011.

[17] Heathwaite, A.L., Dils, R.M., Liu, S., Carvalho, L., Brazier, R.E., Pope, L., Hughes, M., Phillips, G. \& May, L., A tiered risk-based approach for predicting diffuse and point source phosphorus losses in agricultural areas. Sci. Total Environ., 2005.

[18] Hooda, P.S., Edwards, A.C., Anderson, H.A. \& Miller, A., A review of water quality concerns in livestock farming areas. Sci. Total Environ., 2000.

[19] Goldberg, V.M., Groundwater pollution by nitrates from livestock wastes. Environ. Health Perspect., 1989.

[20] Huang, Z., Han, L., Zeng, L., Xiao, W. \& Tian, Y., Effects of land use patterns on stream water quality: A case study of a small-scale watershed in the Three Gorges Reservoir Area. China. Environ. Sci. Pollut. Res., 2016.

[21] Ferreira, A.R.L., Sanches Fernandes, L.F., Cortes, R.M.V. \& Pacheco, F.A.L., Assessing anthropogenic impacts on riverine ecosystems using nested partial least squares regression. Sci. Total Environ., 583, pp. 466-477, 2017.

[22] Soares, H.M.V.M., Boaventura, R.A.R., Machado, A.A.S.C. \& Esteves Da Silva, J.C.G., Sediments as monitors of heavy metal contamination in the Ave River Basin (Portugal): Multivariate analysis of data. Environ. Pollut., 105, pp. 311-323, 1999.

[23] Alves, C., Boaventura, R. \& Soares, H., Evaluation of heavy metals pollution loadings in the sediments of the Ave River Basin (Portugal). Soil Sediment Contam., 18, pp. 603-618, 2009.

[24] Fonseca, A.R., Sanches Fernandes, L.F., Fontainhas-Fernandes, A., Monteiro, S.M. \& Pacheco, F.A.L., From catchment to fish: Impact of anthropogenic pressures on gill histopathology. Sci. Total Environ., 550, pp. 972-986, 2016. 
[25] Ribeiro, C.M.R., Maia, A.S., Ribeiro, A.R., Couto, C., Almeida, A.A., Santos, M. \& Tiritan, M.E., Anthropogenic pressure in a Portuguese river: Endocrine-disrupting compounds, trace elements and nutrients. J. Environ. Sci. Heal.: Part A Toxic/Hazardous Subst. Environ. Eng., 2016.

[26] Dunck, B., Lima-Fernandes, E., Cássio, F., Cunha, A., Rodrigues, L. \& Pascoal, C., Responses of primary production, leaf litter decomposition and associated communities to stream eutrophication. Environ. Pollut., 2015.

[27] ESRI ArcMap 10.1, Environ. Syst. Resour. Inst., 2012.

[28] ESRI ArcHydro Tools for ArcGIS 10: Tutorial, 2012.

[29] De Jesus, H., Sousa, R., Oliveira, R. \& Nery, F., A Componente Geográfica do SNIRH. IV SILUSBA, 1999.

[30] Adamczyk, J. \& Tiede, D., ZonalMetrics: A python toolbox for zonal landscape structure analysis. Comput. Geosci., 99, pp. 91-99, 2017.

[31] Shi, P., Zhang, Y., Li, Z., Li, P. \& Xu, G., Influence of land use and land cover patterns on seasonal water quality at multi-spatial scales. CATENA, 151, pp. 182-190, 2017.

[32] Dow, C.L., Arscott, D.B. \& Newbold, J.D., Relating major ions and nutrients to watershed conditions across a mixed-use, water-supply watershed. J. North Am. Benthol. Soc., 25, pp. 887-911, 2006.

[33] Yong, S.T.Y. \& Chen, W., Modeling the relationship between land use and surface water quality. J. Environ. Manage., 2002.

[34] Uuemaa, E., Roosaare, J. \& Mander, Ü., Scale dependence of landscape metrics and their indicatory value for nutrient and organic matter losses from catchments. Ecol. Indic., 2005.

[35] Lee, S.W., Hwang, S.J., Lee, S.B., Hwang, H.S. \& Sung, H.C., Landscape ecological approach to the relationships of land use patterns in watersheds to water quality characteristics. Landsc. Urban Plan., 2009.

[36] Yu, S., Xu, Z., Wu, W. \& Zuo, D., Effect of land use types on stream water quality under seasonal variation and topographic characteristics in the Wei River Basin, China. Ecol. Indic., 60, pp. 202-212, 2016.

[37] Mahmud, Z.H. et al., Occurrence of Escherichia coli and faecal coliforms in drinking water at source and household point-of-use in Rohingya camps, Bangladesh. Gut Pathog., 11, 2019.

[38] U.S. Environmental Protection Agency, Aquatic life ambient water quality criteria for ammonia: Freshwater. Off. Water, Sci. Technol., 70, 2013.

[39] Araújo, M.F., Valério, P. \& Jouanneau, J.M., Heavy metal assessment in sediments of the Ave River Basin (Portugal) by energy-dispersive x-ray fluorescence spectrometry. X-Ray Spectrom., 1998.

[40] Neary, D.G., Ice, G.G. \& Jackson, C.R., Linkages between forest soils and water quality and quantity. For. Ecol. Manage., 258, pp. 2269-2281, 2009.

[41] Ahearn, D.S., Sheibley, R.W., Dahlgren, R.A., Anderson, M., Johnson, J. \& Tate, $\mathrm{K}$.W., Land use and land cover influence on water quality in the last free-flowing river draining the western Sierra Nevada, California. J. Hydrol., 313, pp. 234-247, 2005.

[42] Pissarra, T.C.T., Valera, C.A., Costa, R.C.A., Siqueira, H.E., Martins Filho, M.V., Valle Júnior, R.F. do, Sanches Fernandes, L.F. \& Pacheco, F.A.L., A regression model of stream water quality based on interactions between landscape composition and riparian buffer width in small catchments. Water, 2019. 